\title{
Laparoscopic versus open nephrectomy in resource-constrained developing world hospitals: a retrospective analysis
}

\author{
Avikar Singh ${ }^{1^{*}}$ (D) and Ronald James Urry ${ }^{2}$ (D)
}

\begin{abstract}
Background: Laparoscopic nephrectomy is the standard of care for nephrectomy in most developed countries. Its adoption in our setting has been limited due to lack of equipment and expertise. This paper sets out to show that laparoscopic nephrectomy is technically feasible in the state sector in South Africa.

Methods: A retrospective chart review was performed of all patients having undergone nephrectomy over a fiveyear period at two state hospitals in KwaZulu-Natal Province, South Africa. Demographic information, pre-operative imaging findings, operative information and post-operative outcomes were analysed.

Results: Nephrectomy was performed in 196 patients. Open nephrectomy (ON) was the intended surgical approach in $73 \%(n=143)$ and laparoscopic nephrectomy $(L N)$ in $27 \%(n=53)$. The conversion rate from $L N$ to ON was $11 \%$ $(n=6)$. For malignancies, there was no difference in surgical resection margin status across the ON, LN and conversion groups; however, tumour size was larger in the conversion group compared to the LN group. Estimated blood loss and transfusion rates were lower in the LN group. The average length of hospital stay was shorter in the LN group (5 vs 10 days). High dependency unit (HDU) admission rate was lower in the LN group (12.1\%) compared to the ON group (50\%) and the conversion group (40\%). No difference in high-grade complications was noted between the ON and LN groups, and more patients in the LN group (82.5\%) had no complications compared to the open group (9.9\%).

Conclusion: $L N$ is non-inferior to $O N$ in terms of operative time, oncology outcomes and high-grade complications. $L N$ is superior in terms of blood loss, transfusion rate, length of hospital stay and overall complication rate. LN appears to show technical feasibility in the state sector and highlights the need for laparoscopic training.
\end{abstract}

Keywords: Nephrectomy, Laparoscopic, South Africa, Developing

\section{Background}

Since laparoscopic nephrectomy was first described by Clayman et al. in 1990 [1], the technique has been embraced worldwide to become the standard of care for patients undergoing nephrectomy. In developing countries, hindrances to the adoption of laparoscopic nephrectomy include lack of access to equipment and lack of expertise. This is true in many government

\footnotetext{
*Correspondence: avikarsingh@gmail.com

${ }^{1}$ Nelson R. Mandela School of Medicine, University of KwaZulu-Natal,

Durban, South Africa

Full list of author information is available at the end of the article
}

hospitals in South Africa, where open nephrectomy remains the standard of care, with an associated high complication rate [2]. This paper sets out to show that laparoscopic nephrectomy is feasible in the state sector in South Africa and that it should be considered the standard of care. Furthermore, it aims to highlight the importance of investment in laparoscopic equipment and training in developing countries. The study was conducted at two state hospitals in KwaZulu-Natal Province, South Africa. KwaZulu-Natal is a large province in South Africa with a population of approximately 10.5 million people and a mixed rural and urban population. Grey's 
Hospital is a tertiary academic hospital in Pietermaritzburg and is the urology referral centre for approximately 3 million people. Saint Aidan's Hospital in Durban is a regional hospital in Durban and is the urology referral centre for approximately 3.4 million people [3].

\section{Methods}

\subsection{Study design and data collection}

A retrospective chart review of all patients having undergone nephrectomy at two state hospitals between 1 January 2011 and 31 December 2015 was performed. Data collected included demographic information, preoperative imaging findings, operative information (surgical approach, operative time, estimated blood loss and transfusion requirements) and post-operative outcomes (histopathology findings, length of hospital stay and complications). Malignancies were staged according to the American Joint Committee on Cancer TNM classification, and complications were categorised according to the Clavien-Dindo classification $[4,5]$.

\subsection{Surgical approaches}

Laparoscopic nephrectomy has been performed at Grey's Hospital since the early 2000s [6]. This was made possible by one part-time urologist undergoing laparoscopic training, and one laparoscopically trained urologist joining the team. This has allowed urology residents to be trained in laparoscopic surgery. A trans-peritoneal technique with en bloc ligation of the renal hilum with a vascular stapler is favoured [6]. Laparoscopic partial nephrectomy is performed for selected small renal masses, and open nephrectomy is reserved for large lesions or complex cases. During the time period of data collection, there were no laparoscopically trained urologists at Saint Aidan's Hospital in Durban, and all nephrectomies were performed via open surgery; however, a laparoscopic service has since been started. Specialists and residents at both hospitals perform surgery.

\subsection{Statistical analysis}

IBM Statistical Package for Social Sciences (SPSS) (IBM Corp, Armonk, NY) was used for statistical analysis. Descriptive statistics (mean and standard deviation or median and interquartile ranges) were calculated. The Pearson Chi-squared test $\left(\chi^{2}\right)$ was used to compare categorical variables. If an expected cell count was less than five observations, the Fischer's Exact test was used. The two-sample Wilcoxon rank-sum (Mann-Whitney) test was used to compare the variables with nonparametric distributions, across subgroups. Likelihood ratios were calculated to assess the likelihood of an event taking place in the presence of a risk factor. A $p$ value of less than 0.05 (5\%) was considered statistically significant.

\section{Results}

During the study period, 196 patients underwent nephrectomy across both hospitals.

\subsection{Patient characteristics and pre-operative diagnosis}

Patient characteristics and indication for nephrectomy divided by intention to treat principle into open or laparoscopic are summarised in Table 1.

The demographics of the patients in the intention to treat open and laparoscopic groups were not significantly different, nor were the starting haemoglobin $(p=0.184)$ and creatinine levels $(p=0.339)$.

There was no significant difference between suspected benign and malignant diagnoses in the intention to treat open and laparoscopic groups $(p=0.899)$. Among the patients with suspected RCC, the mean tumour size on imaging was significantly smaller in the intention to treat laparoscopic group compared to the intention to treat open group $(6.4 \mathrm{~cm}$ vs $10.6 \mathrm{~cm}, p=0.001)$.

Table 1 Patient characteristics and indication for nephrectomy divided by intention to treat open and laparoscopic

\begin{tabular}{|c|c|c|c|c|c|}
\hline & \multicolumn{2}{|l|}{ Open } & \multicolumn{2}{|c|}{ Laparoscopic } & \multirow{2}{*}{$\begin{array}{l}\text { Total } \\
n\end{array}$} \\
\hline & Mean & $n(\%)$ & Mean & $n(\%)$ & \\
\hline Age (years) & 47.6 & & 45.3 & & \\
\hline \multicolumn{6}{|l|}{ Gender } \\
\hline Male & & $69(48 \%)$ & & $25(47 \%)$ & 94 \\
\hline Female & & $74(52 \%)$ & & $28(53 \%)$ & 102 \\
\hline \multicolumn{6}{|l|}{ Race } \\
\hline Black & & $100(70 \%)$ & & $34(64 \%)$ & 134 \\
\hline Indian & & $32(22 \%)$ & & $10(19 \%)$ & 42 \\
\hline White & & $8(6 \%)$ & & $7(13 \%)$ & 15 \\
\hline Mixed & & $3(2 \%)$ & & $2(4 \%)$ & 5 \\
\hline $\begin{array}{l}\text { Pre-op haemoglobin (g/ } \\
\quad \mathrm{dL} \text { ) }\end{array}$ & 11.49 & & 12.72 & & \\
\hline Pre-op creatinine $(\mu \mathrm{mol} / \mathrm{L})$ & 110 & & 118 & & \\
\hline \multicolumn{6}{|l|}{ Indication for nephrectomy } \\
\hline Solid mass & & 69 & & 21 & 90 \\
\hline Cystic mass & & 8 & & 12 & 20 \\
\hline Obstructed NFKa & & 23 & & 9 & 32 \\
\hline Infected NFKa & & 21 & & 7 & 28 \\
\hline NFKa with stones & & 18 & & 1 & 19 \\
\hline Atrophic NFK ${ }^{\mathrm{a}}$ & & 0 & & 2 & 2 \\
\hline Trauma & & 4 & & 1 & 5 \\
\hline Total & & 143 & & 53 & 196 \\
\hline
\end{tabular}

a Non-functioning kidney 


\subsection{Surgical approach}

The breakdown of surgical approaches is summarised in Table 2.

Six patients intended to be treated laparoscopically went on to have conversion to open surgery ( $11 \%$ conversion rate). One conversion was made after pus was found around a kidney in which a renal mass had been suspected on pre-operative imaging. The remaining five conversions were all radical nephrectomies for suspected renal cell carcinoma (RCC), of which four were confirmed to be RCC, and one was found to be a fat-poor angiomyolipoma. These patients all had renal masses larger than $7 \mathrm{~cm}$, and the reasons for conversion were technical difficulty due to the size of the mass, bleeding and injury to adjacent organs (IVC and liver).

\subsection{Histopathological findings}

The histopathological findings at nephrectomy are illustrated in Fig. 1.

The distribution of pathology among intention to treat laparoscopic and open groups was not significantly different $(p=0.325)$. Benign neoplasms identified included angiomyolipoma, oncocytoma, leiomyoma and cystic nephroma. Other malignancies identified included squamous cell carcinoma, leiomyosarcoma, adenocarcinoma and liposarcoma.

\subsection{RCC subgroup}

The tumour characteristics for the 77 patients with RCC are described in Table 3.

There was no difference in surgical resection margin status across the three groups $(p=0.761)$. There was no difference in the $T$ stage $(p=0.08), M$ stage $(p=0.08)$ and grade $(p=0.750)$ between the laparoscopic group and

Table 2 Breakdown of surgical approaches

\begin{tabular}{llllr}
\hline & Open & Laparoscopic & $\begin{array}{l}\text { Laparoscopic converted } \\
\text { to open }\end{array}$ & Total \\
\hline Simple nephrectomy & 66 & 18 & 0 & $84(43 \%)$ \\
Radical nephrectomy & 67 & 17 & 6 & $90(45.9 \%)$ \\
Nephroureterectomy & 9 & 2 & 0 & $11(5.6 \%)$ \\
Partial nephrectomy & 1 & 10 & 0 & $11(5.6 \%)$ \\
Total & $143(73 \%)$ & $47(23.9 \%)$ & $6(3.1 \%)$ & $196(100 \%)$ \\
\hline
\end{tabular}

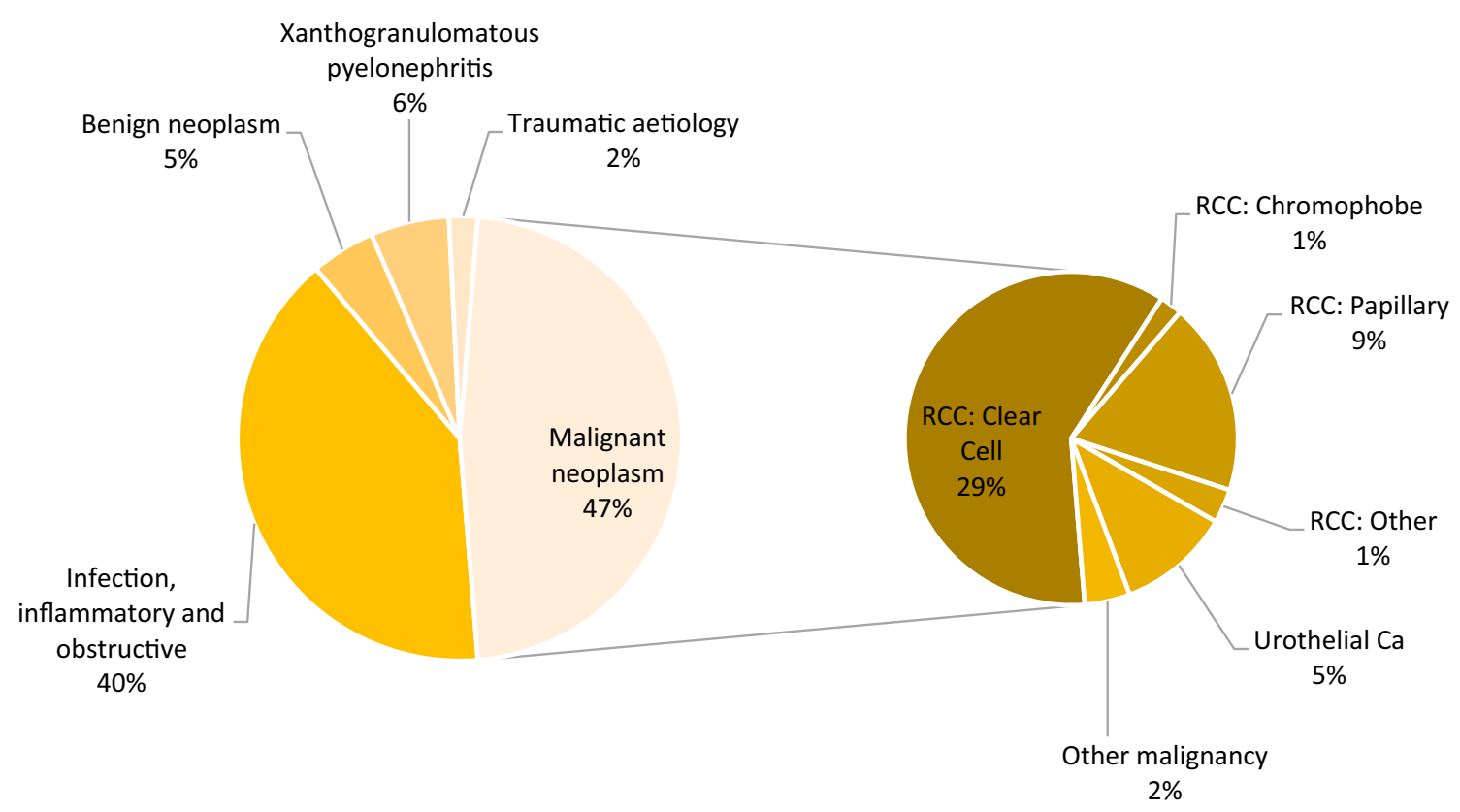

Fig. 1 Distribution of histopathology findings at nephrectomy 
Table 3 Tumour characteristics of RCCs $(n=77)$

\begin{tabular}{|c|c|c|c|}
\hline & Open $\mathrm{n}(\%)$ & Laparoscopic $n(\%)$ & $\begin{array}{l}\text { Laparoscopic } \\
\text { converted to open } \\
n(\%)\end{array}$ \\
\hline Median tumour size at histopathology $(\mathrm{cm})$ & 10.6 & 5.8 & 11.5 \\
\hline \multicolumn{4}{|l|}{ Tstage } \\
\hline T1a & $6(10.7)$ & $6(35.3)$ & $0(0)$ \\
\hline $\mathrm{T} 1 \mathrm{~b}$ & $7(12.5)$ & $4(23.5)$ & $0(0)$ \\
\hline T2a & $12(21.4)$ & $1(5.9)$ & $0(0)$ \\
\hline $\mathrm{T} 2 \mathrm{~b}$ & $20(35.7)$ & $1(5.9)$ & $3(75.0)$ \\
\hline T3a & $9(16.1)$ & $3(17.6)$ & $1(25.0)$ \\
\hline $\mathrm{T} 4$ & $2(3.6)$ & $1(5.9)$ & $0(0)$ \\
\hline Not specified & $0(0)$ & $1(5.9)$ & $0(0)$ \\
\hline \multicolumn{4}{|l|}{ N stage } \\
\hline No & $34(60.7)$ & $3(17.6)$ & $0(0)$ \\
\hline N1 & $10(17.9)$ & $0(0)$ & $2(50.0)$ \\
\hline $\mathrm{Nx}$ & $12(21.4)$ & $14(82.4)$ & $2(50.0)$ \\
\hline \multicolumn{4}{|l|}{ M stage } \\
\hline Mo & $50(89.3)$ & $15(88.2)$ & $2(50.0)$ \\
\hline M1 & $6(10.7)$ & $2(11.8)$ & $2(50.0)$ \\
\hline Mx & $0(0)$ & $0(0)$ & $0(0)$ \\
\hline \multicolumn{4}{|l|}{ Fuhrman grade } \\
\hline Grade 1 & $4(7.1)$ & $2(11.8)$ & $0(0)$ \\
\hline Grade 2 & $21(37.5)$ & $8(47.1)$ & $2(50.0)$ \\
\hline Grade 3 & $24(42.9)$ & $3(17.6)$ & $1(25.0)$ \\
\hline Grade 4 & $6(10.7)$ & $0(0)$ & $0(0)$ \\
\hline Not specified & $1(1.8)$ & $4(23.6)$ & $1(25.0)$ \\
\hline \multicolumn{4}{|l|}{ Resection margins } \\
\hline Clear & $49(87.5)$ & $15(88.2)$ & $3(75.0)$ \\
\hline Positive & $7(12.5)$ & $2(11.8)$ & $1(25.0)$ \\
\hline Not specified & $0(0)$ & $0(0)$ & $0(0)$ \\
\hline
\end{tabular}

the conversion to open group. The tumour size was significantly larger $(p=0.005)$, and there were significantly more patients with positive lymph nodes $(p=0.008)$ in the conversion to open group compared to the laparoscopic group. Following regression analysis, extra-renal extension and size greater than $7 \mathrm{~cm}$ were not found to be significant risk factors for conversion to open.

\subsection{Outcomes and complications}

The intraoperative and post-operative outcomes for the three groups are summarised in Table 4.

The operative time was not significantly different between the open and laparoscopic groups $(p=0.001)$ but was significantly longer in the conversion group. The blood loss was significantly higher in both the open $(p=0.005)$ and conversion $(p<0.001)$ groups compared to the laparoscopic group. Correspondingly, there was a significantly lower transfusion rate in the laparoscopic group. The rate of HDU admission was significantly less, and the mean hospital length of stay (LOS) was significantly shorter in the laparoscopic group compared to the open and conversion groups.

The grading of the complications according to the Clavien-Dindo classification over the three groups is summarised in Table 4, with details of severe complications in Table 5 . Death of the patient is classified as grade 5 .

The laparoscopic group had significantly more patients with no complications compared to the open and conversion groups $(p<0.001)$. Serious complications (ClavienDindo grade 3-5) occurred in 17 (12.0\%), 3 (7.5\%) and 2 (33.3\%) of patients in the open, laparoscopic and conversion groups, respectively. There was no significant difference in severe complications among the three groups $(p=0.154)$.

The overall mortality rate after nephrectomy was $3.1 \%$. There were 5 mortalities in the open nephrectomy group and 1 in the laparoscopic group. These included 3 patients with perioperative cardiac events, two with 
Table 4 Intra- and post-operative outcomes

\begin{tabular}{|c|c|c|c|c|}
\hline & Open & Laparoscopic & $\begin{array}{l}\text { Laparoscopic converted } \\
\text { to open }\end{array}$ & $p$ value \\
\hline Mean operative time (min) & 113 & 111 & 192 & $<0.001$ \\
\hline Mean estimated blood loss in theatre $(\mathrm{mL})$ & 311 & 159 & 810 & $<0.001$ \\
\hline Number of patients drain placed intraoperatively $(n(\%))$ & $124(87.9)$ & $27(60.0)$ & $6(100.0)$ & $<0.001$ \\
\hline Number of patients transfused $(n(\%))$ & $63(45.0)$ & $2(6.1)$ & $3(75.0)$ & $<0.001$ \\
\hline Admission to high dependency unit (HDU) $(n(\%))^{\mathrm{a}}$ & $14(50.0)$ & $4(12.1)$ & $2(40.0)$ & 0.005 \\
\hline Mean hospital length of stay (days) & 10 & 5 & 10 & 0.021 \\
\hline \multicolumn{5}{|l|}{ Clavien-Dindo complications } \\
\hline None & $14(9.9)$ & $33(82.5)$ & $2(33.3)$ & \\
\hline Grade 1 & $62(43.7)$ & $3(7.5)$ & $1(16.7)$ & \\
\hline Grade 2 & 49 (34.5) & $1(2.5)$ & $1(16.7)$ & \\
\hline Grade 3a & $4(2.8)$ & $1(2.5)$ & $0(0.0)$ & \\
\hline Grade 3b & $7(4.9)$ & $0(0.0)$ & $1(16.7)$ & \\
\hline Grade 4a & $0(0.0)$ & $0(0.0)$ & $1(16.7)$ & \\
\hline Grade $4 b$ & $1(0.7)$ & $1(2.5)$ & $0(0)$ & \\
\hline Grade 5 & $5(3.5)$ & $1(2.5)$ & $0(0)$ & \\
\hline
\end{tabular}

a Data regarding HDU admission from Saint Aidan's Hospital in Durban were not available

Table 5 Details of severe complications

\begin{tabular}{|c|c|c|c|}
\hline & Open & Laparoscopic & Laparoscopic converted to open \\
\hline Grade 3 & $\begin{array}{l}11 \\
\text { IVC injury repaired intraoperatively-3 } \\
\text { Repeat surgery } \\
\text { Wound infection-3 } \\
\text { Pneumothorax requiring intercostal drain- } \\
\text { age-2 } \\
\text { Relaparotomy for } \\
\text { Delayed bleed }-1 \\
\text { Pancreatic injury-1 } \\
\text { Prolonged ileus }-1\end{array}$ & $\begin{array}{l}1 \\
\text { Wound infection: flank abscess requiring } \\
\text { percutaneous drainage }\end{array}$ & $\begin{array}{l}1 \\
\text { IVC injury repaired intraoperatively }\end{array}$ \\
\hline Grade 4 & $\begin{array}{l}1 \\
\text { IVC Injury/MOD/TF ICU/demised }\end{array}$ & $\begin{array}{l}1 \\
\text { Urinoma requiring complete nephrectomy, } \\
\text { Bowel perf } X 3 \text { repaired, ECF development, } \\
\text { intra-abd sepsis }\end{array}$ & $\begin{array}{l}1 \\
\text { IVC Injury—Repaired intraoperatively, AKI } \\
\text { secondary to hypotension-Resolved } \\
\text { (Cr 1090 } 233) \text {, transfusion }\end{array}$ \\
\hline Grade 5 & $\begin{array}{l}5 \\
\text { Hypovolemia with Perioperative Myocardial } \\
\text { infarction, Renal failure, (Multiorgan Failure). } \\
\text { Patient demised in ICU } \\
\text { latrogenic Splenic injury which was packed, } \\
\text { Sepsis, Cardiac arrest with suspected Myo- } \\
\text { cardial Infarction, deemed not a candidate } \\
\text { for ICU. Patient demised } \\
\text { Patient with end-stage renal failure and } \\
\text { pneumonia, not a candidate for the chronic } \\
\text { renal programme, sent to renal for ESRD and } \\
\text { uncontrolled hypertension. Patient demised } \\
\text { Suspected perioperative Myocardial infarc- } \\
\text { tion exacerbated by hypovolemia, patient } \\
\text { demised } \\
\text { Patient post-chemotherapy, with anaemia } \\
\text { requiring transfusion. The patient subse- } \\
\text { quently demised of suspected myocardial } \\
\text { infarction (Late) }\end{array}$ & $\begin{array}{l}1 \\
\text { Prolonged bleeding postop requiring explora- } \\
\text { tory laparotomy. Patient demised after } \\
\text { massive transfusion }\end{array}$ & 0 \\
\hline
\end{tabular}


multiorgan failure in ICU, one with renal failure and one with advanced disease after a palliative nephrectomy. The patient who died after laparoscopic nephrectomy had a late bleed in the HDU, required relook open surgery, was transfused 11 units of blood and demised from complications of massive transfusion and ongoing bleeding.

\section{Discussion}

The widespread adoption of laparoscopic nephrectomy by South African urologists appears to be taking longer than some of our international colleagues [1]. While laparoscopic radical nephrectomy (LRN) has been shown to be at least as effective and safe as open radical nephrectomy (ORN) in achieving oncological control, with the added benefits of minimal invasiveness, there is a tendency to perform ORN in larger tumours, and the decision to perform minimally invasive surgery is influenced by training experience [7-9]. One of two facilities described in this study performed only ORN, due to a lack of training as well as various resource constraints [2].

These data aim to describe the technical feasibility of LN in a developing setting starting up a laparoscopy service. A recent meta-analysis reiterated that laparoscopic radical nephrectomy was associated with improved perioperative outcomes compared to the open approach [7]. Although the technique has been shown to be technically and financially feasible in developing and developed settings where it is performed in high volume, the technical feasibility in our setting had not been evaluated to date [10].

In the state sector in $\mathrm{KZN}$, only one of the two institutions described performed laparoscopic nephrectomy during the data collection period. This is thought to be due to a shortage of laparoscopically trained urological surgeons in the state health care sector.

Two specialists were formally trained in laparoscopic surgery; one part-time urologist undergoing laparoscopic training, and one laparoscopically trained urologist joining the team. This has allowed urology residents to be trained in laparoscopic surgery. As this is a training institution, urology residents have also been involved in the surgery; however, the extent of this involvement has not been routinely documented. In recording the surgical case, the consultant surgeon and resident is recorded. The authors did not find any significant difference between specialists or resident involved.

Forty-six laparoscopic nephrectomies were performed, forming 24 per cent of all nephrectomies. The conversion rate of 11 per cent of laparoscopic cases to open consisted of 6 radical nephrectomies, 4 of which were for tumours $7 \mathrm{~cm}$ or larger. This is higher than described by larger databases; the British Association of Urologic surgeons nephrectomy database reports a 5.5 per cent conversion rate [11]. This lower threshold of surgeons to convert to an open procedure suggests that they are still on the learning curve for complex cases, and will likely improve with higher laparoscopic volume [12].

The pathology specimens indicated 47 per cent of nephrectomy specimens showed malignancy. Benign neoplasms formed 5 per cent of specimens and usually followed nephron-sparing partial nephrectomy or simple nephrectomy in the case of bleeding angiomyolipomas. The large proportion of nephrectomy for infective, inflammatory and obstructive aetiology can once again be attributed to delayed access to appropriate health care and referral pathways, a current persistent limitation of the state health care sector.

Patients with HIV appeared to present at significantly younger ages compared with their non-HIV counterparts; however, this significance did not persist after multivariate regression. Regardless, this trend of HIV decreasing age of presentation in RCC has been suggested before, and it is worthwhile interrogating this relationship in the future [13]. Following regression analysis, age remained a risk factor for RCC in our analysis.

The operative times appear to be comparable in open and laparoscopic nephrectomy with no significant difference. The estimated blood loss and transfusion rates are significantly lower in the laparoscopy groups than the open groups. In a recent study at one of the centres we looked at, the authors noted a high transfusion rate in open nephrectomy at Saint Aidan's Hospital [2]. At Grey's Hospital, where a more restrictive transfusion strategy is employed, the transfusion rates remained significantly lower in the laparoscopy group, and overall Grey's Hospital transfusion rates are lower than described in the literature for nephrectomy [11].

Patients' average length of stay was significantly shorter in the laparoscopy group (5 vs 10 days), even in the LRN group (6 vs 8 days). This represents a significant benefit to the patient in terms of faster convalescence as well as the cost of hospital stay [11].

There were 5 mortalities in the open nephrectomy group and 1 in the laparoscopic group. No significant difference in severe complications existed between the open and laparoscopic groups, although it should be noted that significantly more patients in the laparoscopy group $(82.5 \%)$ had no complications, compared to the open group (9.9\%). The described severe complications are expected for the surgery performed. Wound infection requiring debridement occurred exclusively in patients requiring nephrectomy for infective indication. However, particular attention should be paid to washout and drainage of these patients intraoperatively, with appropriate wound care. Intraoperative haemorrhage due to IVC injury or gonadal vein avulsion has been minimised 
by consistently aiming for optimal exposure and meticulous dissection, with en bloc control of the hilum with a stapler device [6]. ICU complications of the patients post-nephrectomy are commonly related to hypovolemia; thus, all attempts should be made to prevent bleeding, with appropriate and prompt support of patients who do haemorrhage.

From this experience, it can be seen that laparoscopic nephrectomy is non-inferior to open nephrectomy in qualifying patients in terms of operative time and complications. Furthermore, it appears to offer an advantage in blood loss, hospital stay and low-grade complications.

This study is limited by the retrospective nature and lack of equal numbers in each group. The lack of significant difference between resection margin status in the laparoscopic over the open group is promising; however, term follow-up survival data are required to reinforce oncological equivalence of the approaches. Although there are likely selection bias and a lack of comparative groups on choosing minimally invasive surgery over open surgery in terms of smaller tumour sizes, the distribution of pathology in each group was not significantly different. Additionally, the distribution of comorbidities and risk factors was not significantly different among groups. Mean tumour sizes were significantly smaller in the laparoscopy group. This is one of the major limitations of the study and can be alleviated by a larger-scale study in the future with inclusion and exclusion criteria.

The current perception in South African state health care sector, as well as medical schemes, is that LRN is at a higher cost financially due to running and equipment costs; however, further research into the cost-effectiveness in our resource-limited environment is still needed. The expenditure associated with minimally invasive nephrectomy has yet to be described in the South African setting. In an environment with constrained resources, where anticipated financial expenditure may hinder the adoption of a particular therapy, an analysis of the actual expenditure associated with both modalities should be undertaken. The authors recommend that further evaluation of the actual financial cost to state will enable the financial feasibility of minimally invasive surgery to be established as a viable option for the state, in addition to the numerous benefits to the patient. This evaluation should weigh up the cost of disposables for LN against the savings in bed-nights, blood products, ICU admissions and cost of managing complications.

\section{Conclusion}

$\mathrm{LN}$ is non-inferior to $\mathrm{ON}$ in terms of operative time, oncological parameters and high-grade complications. $\mathrm{LN}$ is superior in terms of blood loss, transfusion rate, length of hospital stay and overall complication rate. LN appears to show technical feasibility in the state sector and highlights the need for laparoscopic training.

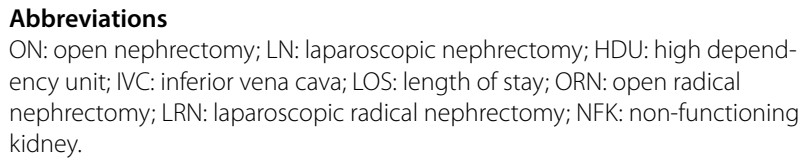

\section{Acknowledgements}

The authors acknowledge Hainsworth, Purcell \& Partners pathologists, Jackie Pillay (Urology department, Greys Hospital urology) and Dr. Siaka Lougue (biostatistician) for their assistance.

\section{Authors' contribution}

Both authors were involved in study protocol development, data collection, data analysis and final manuscript writing. All authors read and approved the final manuscript.

Funding

Not applicable.

\section{Availability of data and materials}

The datasets used and/or analysed during the current study are available from the corresponding author on reasonable request.

\section{Ethics approval and consent to participate}

This study was approved by the Biomedical Research Ethics Committee of the University of KwaZulu-Natal (BE258/16). Consent to participate was not applicable as this was a retrospective chart review. This decision to waiver was approved by the Biomedical Research Ethics Committee of the University of KwaZulu-Natal (BE258/16).

\section{Consent for publication}

Not applicable.

\section{Competing interests}

The authors declare that they have no competing interests.

\section{Author details}

${ }^{1}$ Nelson R. Mandela School of Medicine, University of KwaZulu-Natal, Durban, South Africa. ${ }^{2}$ Sefako Makgatho Health Sciences University, Ga-Rankuwa, South Africa.

Received: 2 July 2020 Accepted: 17 November 2020 Published online: 11 December 2020

\section{References}

1. Clayman RV, Kavoussi LR, Soper NJ (1991) Laparoscopic nephrectomy. N Engl J Med 324:1370-1372. https://doi.org/10.1056/NEJM19910509324 1917

2. Singh A, Urry R, Hardcastle T (2018) Five year review of open radical nephrectomies at a regional hospital in South Africa: room for improvement. SAJS 01(56):35-39. https://doi.org/10.17159/2078-5151/2018/ v56n1a2195

3. Statistics South Africa (2012) Census 2011 Census in brief. [Online].: Statistics South Africa; 2012 [cited 201812 February. Available from: www.stats sa.gov.za/census/census_2011/census./Census_2011_Census_in_brief .pdf

4. Edge SBBDCCFAGFTA (2010) AJCC cancer staging manual, 7th edn. Springer, New York

5. Dindo D, Demartines N, Clavien PA (2004) Classification of surgical complications: a new proposal with evaluation in a cohort of 6336 patients and results of a survey. Ann Surg 240(2):205-213 [PMID: 15273542]

6. Conradie MC, Urry RJ, Naidoo D, Mahmood K, Jogiat Z, Alsharef M et al (2009) Advantages of en bloc hilar ligation during laparoscopic 
extirpative renal surgery. J Endourol 23(9):1503-1507. https://doi. org/10.1089/end.2009.0380

7. Liu G, Ma Y, Wang S, Han X, Gao D (2017) Laparoscopic versus open radical nephrectomy for renal cell carcinoma: a systematic review and meta-analysis. Transl Oncol 10(4):501-510. https://doi.org/10.1016/j.trano n.2017.03.004

8. European Association of Urology. European association of urology. [Online].: European Association of Urology; 2020. Cited 202008 10. Available from: http://uroweb.org/quideline/renal-cell-carcinoma/

9. Kercher KW, Heniford BT, Matthews BD, Smith TI, Lincourt AE, Hayes DH et al (2003) Laparoscopic vs open nephrectomy in 210 consecutive patients. J Surg Endosc 17:1889-1895. https://doi.org/10.1007/s0046 4-003-8808-3

10. Alemozaffar M, Chang SL, Kacker R, Sun M, DeWolf WC, Wagner AA (2013) Comparing costs of robotic, laparoscopic, and open partial nephrectomy. J Endourol 27(5):560-565. https://doi.org/10.1089/end.2012.0462

11. Henderson JM, Fowler S, Joyce A, Dickinson A, Keeley FX, BAUS (2012) Perioperative outcomes of 6042 nephrectomies in 2012 surgeon-reported results in the UK from the British Association of Urological Surgeons (BAUS) nephrectomy database. Br J Urol Int 2014(115):121126. https://doi.org/10.1111/bju.12770

12. Masoud M, Ibrahim A, Elemam A, Elatreisy A, Noureldin Y, Aubé M, Fahmy N (2020) Learning curve of laparoscopic nephrectomy: a prospective pilot study. Afr J Urol. https://doi.org/10.1186/s12301-020-00024-x

13. Gaughan EM, Dezube BJ, Aboulafia D, Bower M, Stebbing J, Powels T et al (2008) Human immunodeficiency virus-associated renal cell carcinoma: a transatlantic case series. Clin Genitour Cancer. 6(2):86-90. https://doi. org/10.3816/CGC.2008.n.013

\section{Publisher's Note}

Springer Nature remains neutral with regard to jurisdictional claims in published maps and institutional affiliations.

\section{Submit your manuscript to a SpringerOpen ${ }^{\circ}$ journal and benefit from:}

- Convenient online submission

- Rigorous peer review

- Open access: articles freely available online

- High visibility within the field

- Retaining the copyright to your article

Submit your next manuscript at $\boldsymbol{\nabla}$ springeropen.com 